\title{
SI EDIPO HABLASE GALLEGO...
}

TERESA MOURE

\author{
Universidade de Santiago de Compostela
}

Este trabajo pretende interpretar la literatura gallega como producto cultural contra-poder, confeccionado sobre una lengua perseguida, lo que obliga a una serie de decisiones conscientes por parte de quien escribe y condiciona la lectura final, otorgándole una condición inequívocamente transgresora. La autora no pretende tanto una visión objetiva y neutra como explicar su propia experiencia como escritora y contribuir al debate con un relato de parte, voluntariamente subjetivo, lo que en ningún caso significa falso.

PALABRAS CLAVE: Identidad nacional, productos culturales subversivos, queer nation, normativas ortográficas en gallego-portugués.

\section{If Oedipus spoke Galician...}

This article interprets Galician literature as a cultural product of resistance constructed in and by a persecuted language. The status of the language calls for a series of conscious decisions by the writer and also influences how the work will be read, bestowing it with an unequivocally transgressive force. The author does not propose to offer an objective and neutral perspective but to explain her own experience as a writer and to contribute to the debate with a partial and intentionally subjective account, which by no means makes it false.

KEY WORDS: National identity, subversive cultural products, Queer nation, normative GalicianPortuguese spelling.

\section{Introducción}

A veces las culturas, como Edipo, aparecen situadas, sin saber bien por qué, en una encrucijada. La encrucijada es el territorio del dilema. Puede aparentar un lugar sugerente, donde deleitarse en el placer de ejercer una elección libre, pero es también el sitio donde desprenderse de algo que durante un tiempo Edipo arrastró consigo, que lo constituyó. Edipo, el de Tebas, habita profundamente el territorio de la encrucijada. Como todos los personajes míticos, está condenado a mantenerse ahí y a repetir su historia, una vez tras otra, fuera del tiempo y del espacio, lo que es tanto como sugerir que Tebas también puede ser Galicia. En la encrucijada, se ve compelido a escoger un camino, aunque la decisión, como tal acto voluntario, exceda con mucho sus heroicas posibilidades. Porque su futuro está escrito y, quiera o no, matará a su padre y gozará de su madre pero no por 
voluntad de poder ni desorden erótico alguno: él es, como diría Shakespeare, apenas un juguete del destino. Inexorablemente tendrá que sufrir la culpa y arrancarse los ojos.

Me decido por la belleza radical de este personaje de tragedia para interpretar la literatura y el conjunto de la cultura gallega en la contemporaneidad. Aunque este Edipo que recreo no se verá en el dilema una vez, sino cuatro. Cuatro son las encrucijadas que atraviesa; cuatro son las incógnitas: cuatro veces la literatura gallega es Edipo.

\section{Primera encrucijada: ser es ser contra otro}

Si el hispanismo consiste en el estudio de unas determinadas producciones literarias y culturales, comenzaremos apuntando una primera tensión conceptual. La etiqueta de hispanismo, ¿se refiere a los productos elaborados en una lengua, el español, en cualquier parte —en Madrid, en Bogotá, en México D.F.—? $\mathrm{O}$, al contrario, ¿importa, para dar pleno sentido al término, el mapa geopolítico, ese que se aplica cuando se distingue literatura española de hispanoamericana? Si aceptamos la versión lingüística, en la literatura hispánica no entrará lo escrito en gallego y quedamos fuera, apenas invitados por cortesía. La nuestra será una literatura vecina y el uso de la herramienta español distinguirá nítidamente el campo del hispanismo, ya sea en el México de las lenguas mayas, en la Cataluña independentista o en el Burgos del Cid. En el segundo caso, ateniéndonos a los límites espaciales de un supuesto territorio común, el del estado español, la literatura gallega adoptaría la forma de una literatura regional. Voy a intentar demostrar, precisamente, que la encrucijada aquí no permite ninguna de estas dos opciones, igual que Edipo no es exactamente asesino ni exactamente inocente; es alguien que habita el conflicto, que se nutre de él... y que produce una realidad emergente, que no se sigue directamente de las premisas dadas por la esfinge.

Voy a considerar las "otras literaturas peninsulares", como a veces son llamadas, desde un punto de vista algo más ácido del implícito en esa etiqueta supuestamente neutra. La literatura gallega, como la catalana o la vasca $-\mathrm{y}$ habría que ver si también las literaturas en lenguas amerindias en las naciones colonizadas por el español- son espacios alternativos, elaborados en los márgenes del poder $\mathrm{y}$, como se sabe, los márgenes son territorios para la libertad y para la disidencia.

Estas realidades culturales no se constituyeron alrededor del español o colaborando con él. Por pura honestidad intelectual, si quisiésemos describir el proceso, habría que reconocer que, al menos a partir de la Edad Media - cuando los trovadores jugaban al plurilingüismo en sus composiciones-, las literaturas en las otras lenguas se elaboran como parte de procesos políticos de identidad y de resistencia: son procesos contra el español. Ser nunca es ser sin más. Soy yo 
porque no soy tú, y la primera persona de la gramática verbal se convierte en un grito de rebeldía.

Además, la literatura en gallego-portugués no existiría hoy con esa felicidad del escritor o la escritora que, bajo su propia inspiración, se sienta a escribir, porque esa naturalidad ni siquiera existe en la sociedad. Todavía hoy, cuando las escritoras y escritores profesionales hemos cursado lengua gallega como materia de estudio en la enseñanza obligatoria, lo cierto es que la hegemonía del español continúa siendo evidente. Ni el currículum escolar, ni la situación social de la lengua aseguran la igualdad de competencias con el español. Es cierto que el tradicional modelo diglósico ha cambiado ligeramente con la introducción del gallego en la docencia y en algunos medios de comunicación y estos pasos andados aseguran que nadie hoy sea llamado "rural", "inculto" o "tosco" por expresarse en la lengua propia. Pero eso no significa que se haya caminado hacia delante y con firmeza en su restitución: el abandono de la lengua entre las generaciones más jóvenes, que el estándar sea calificado de artificioso por los hablantes de distintas procedencias o la identificación del gallego con el idioma de la administración y la protesta política podrían interpretarse como indicio de otras eventuales diglosias, entendiendo el fenómeno, en sentido amplio, como una competencia entre dos idiomas en contacto dictada por criterios sociales que hagan uno preferible al otro en determinados contextos.

Como lingüista profesional, puedo certificar lo que en la calle es un secreto a voces: las personas formadas, incluso con altos niveles de instrucción, en la Galicia actual no son exactamente bilingües. Quien habla y escribe gallego habitualmente tendrá también un alto conocimiento de español pero no a la inversa: quien habla español puede vivir su existencia entera no expresándose nunca en gallego... o haciéndolo declaradamente mal. Otro asunto es que, dada la proximidad genética y tipológica de estas dos lenguas románicas, muchas personas español-hablantes imaginen que están hablando gallego, si la situación así lo demanda, cuando hacen calcos del español en el léxico; muchos se sorprenderían si se les preguntase por una estructura sintáctica del gallego distinta de las del español. La tendencia en los idiomas que compiten en un territorio determina habitualmente que la lengua mejor asentada en el poder ejerza una fuerte influencia, de manera que la otra mimetice sus recursos: use sus interjecciones o sus enlaces, o arrincone las estructuras gramaticales que la lengua dominante no conoce. Por eso en nuestra sociedad son muchas las personas que creen hablar en gallego sin usar los rasgos idiosincráticos que distinguen esta lengua del español: brevemente, sin futuro de subjuntivo, sin infinitivos flexionados, sin complementos directos preposicionales (tipo comín no caldo) o con los enlaces oracionales directamente tomados del español: esos bueno que salpican las conversaciones.

Así pues, la competencia real en gallego parece secundaria (o está secundarizada) $\mathrm{y}$, finalmente, cualquiera de nosotros, los escritores y escritoras, 
podría expresarse con mayor seguridad en español, porque que una lengua sea la dominante implica que los hablantes de la otra con que compite tienen - por ejemplo, a la hora de hacer chistes, o cuando se buscan registros juveniles o recursos expresivos coloquiales- que recurrir a lo que realmente existe. Uno de los problemas de narrar en gallego es que muchos diálogos resultan inverosímiles, puesto que determinados personajes tendrían por fuerza que expresarse en español. Cuando me traduzco al español observo también la cantidad de expresiones orales y coloreadas que tengo a mi disposición y que en gallego resultarían rebuscadas, cultísimas o simplemente forzadas porque el gallego todavía no es una lengua "normal".

Hace unos años, conversando con mi amiga, la escritora madrileña Belén Gopegui, hablamos mucho de lengua. Aunque como persona sensible que ella es, comprendía el proyecto de resistencia que supone la literatura para quien escribe en gallego, no dejaba de sorprenderse. Le sorprendía que acudiésemos a cualquier pueblo distante de nuestras casas sin cobrar - que es lo habitual en cualquier trabajo físico o intelectual- por el simple deseo de que se celebrase un acto en nuestra lengua. Le sorprendía el nivel de compromiso y de militancia con que se mantiene esta lengua en pie. Eran éstas sorpresas gratas para una persona comprometida como ella. Pero tal vez lo que le causaba mayor extrañeza era nuestra obsesión con la lengua, con depurarla, con poner a prueba su versatilidad, con la necesidad de performar mentalmente las situaciones que se describen en la literatura para verificar su naturalidad en un país de esquizoglosia absoluta. Ella - me insistía - al escribir sólo retenía en la cabeza las cuestiones relativas al propio acto de creación, a la coherencia de los personajes: la lengua, su calidad o su corrección, le daba igual. Supongo que Belén Gopegui goza de los beneficios de una lengua normal, una lengua que las personas creadoras usan para producir sus artefactos, una lengua que es medio para un fin. En Galicia, en cambio, la lengua no es un simple vehículo, sino la masa con que levantamos el edificio de la propia cultura, de la propia cosmovisión; es un arma de resistentes.

Si pensamos en la lengua ahora como una herramienta de expresión estética, el gallego en su propia sociedad juega en abierta desventaja. Como consecuencia, la escritura ha adoptado un perfil militante que condiciona la producción literaria. A veces se habla del valor, para lograr altas cotas de excelencia literaria, de los escritores letra-heridos, que adoran la literatura como arte, como pura estética y, probablemente, sea difícil encontrar en la literatura gallega, ejemplares de ese tipo - quizás Carlos Caneiro-, precisamente porque la escritura militante impone su propia lógica.

Se sigue de aquí que el hispanismo pase a ser visto en Galicia como el estudio de la literatura y de la cultura que el reino de España convirtió en herramienta política, en el estado y allende los mares. En ese sentido, contemplar la literatura y la cultura en gallego sirve para completar la óptica de la cultura hecha en la península, en tanto que examen de las literaturas y culturas disidentes, que 
ocupan las brechas de esa hegemonía y pretenden volverse contra ella. Porque, yendo a datos concretos, un análisis de las revistas de crítica literaria o de las recomendaciones culturales en periódicos de gran impacto como El País o $A B C$ permitiría pensar que no existe en el Estado literatura de calidad que no se haya escrito en español. Rara vez un texto en gallego, catalán o euskera llega a esos escaparates de exposición y, cuando sucede, es porque antes han sido traducidos al español, no porque se pretenda dar cuenta de la diversidad cultural. Y las traducciones también tienen su intrahistoria. Tengo mi propia anécdota sobre este asunto.

En 2005 una novela de mi autoría, Herba moura, ganaba una cierta visibilidad al obtener varios premios prestigiosos. La editorial Lumen, del grupo Mondadori, se interesó por su traducción cuando conoció una versión previa al catalán - porque las literaturas disidentes sí se leen entre ellas. En ese momento, compró a Xerais los derechos internacionales para la explotación de la obra y la publicó como Hierba mora, de la que se hicieron varias ediciones, incluidas algunas en formato best-seller. Pues bien, ninguna de esas ediciones indicaba, a pesar de la expresa incomodidad de la autora, que procedía de un original en gallego: apareció como una obra original en español, y como tal se difundió después en otras lenguas a las que fue traducida. Ése es el trato habitual de los autores gallegos cuando publicamos en español, —según mis colegas, con opiniones diversas sobre tan espinoso asunto, me fueron contando-; un trato contra el cual es obligado reaccionar. Pero el problema todavía se complica más. En el proceso de traducción y de corrección de pruebas, se me indicó que debía suprimir algunos capítulos, puesto que, en opinión de la editora, poseían un aire de realismo mágico ya demodé después del boom latinoamericano. Insistí en que esos capítulos formaban parte del relato con la misma propiedad que los demás y que, además, no procedía ningún cambio porque se trataba de un texto ya fijado y publicado. Finalmente, el criterio de la editora prevaleció - fueron eliminados en la Tercera parte, algunos fragmentos del capítulo 11 y del 15, además de la totalidad de los capítulos 12, 16, 27 y 28. Como las traducciones posteriores a otras lenguas se hicieron a partir del texto en español - recuérdese que se había omitido la existencia de un original en gallego-, tenemos en circulación dos textos distintos: el íntegro, con su realismo mágico calificado reiteradamente de cunqueiriano, y el mutilado, según los gustos de la literatura española, bastante más recatada y menos exagerada que mi tribu.

La primera encrucijada nos sitúa, por tanto, ante tres premisas.

Primera: la cultura gallega apenas puede ser interpretada en el contexto de una herida mal cerrada. Como todo el mundo sabe, España se rompe. Sé que los procesos independentistas que sin duda viviremos no resultan interesantes para la academia, que tiende a situarse ajena a este tipo de asuntos políticos por considerarlos circunstanciales. Sin embargo, para entender las producciones culturales en "otras lenguas" es importante entender la herida. Si el estado fuese 
plurilingüe y democrático, reconocería como riqueza la diversidad. Pero en el estado español las otras lenguas se desprecian. Que Almudena Grandes o PérezReverte sean afamados y sus nombres reconocibles, incluso para quien nunca los lee, mientras que Carlos Quiroga, Chus Pato y Séchu Sende, o Rosa Aneiros, Alberto Lema y Xurxo Borrazás, autores de obras bastante más originales y universales no lo sean de la misma manera, indica claramente lo que se quiere decir con hegemonía: la imposición de un relato acorde con el poder.

Segunda premisa: Una mirada ingenua tiende a concluir que todo producto de calidad acabará por abrirse paso, que será traducido y reconocido. Sin embargo, sabemos que existen fuertes intereses que explican que el problema nacional no pueda ser nombrado. Siendo por esencia resultado del problema nacional, la literatura gallega se omite de los catálogos. Cuando, excepcionalmente, aparezca será despojada de su condición transgresora esencial: la galleguidad.

Tercera: al no tener auditorio en el exterior, la literatura gallega corre continuamente el riesgo de volver sobre sí misma y acabar sirviendo a sus propios auditorios, incluso cuando sabemos que la literatura no tiene amo, tribuno ni dios. Si la lectura en gallego va destinada al activismo militante, a los simpatizantes de la causa política, o al público escolar, algunas temáticas están abocadas al fracaso. Las novelas deben ajustarse a un número de páginas que sea aceptable como lectura en los centros de enseñanza, los asuntos tienden al didactismo de lo que se entiende como literatura infantil y juvenil e incluso los formatos repiten las formas clásicas. Puedo documentar como cuando quisimos, por ejemplo, introducir el álbum ilustrado - en mi opinión, un formato artístico que debe ser rescatado en una época de crisis del libro impreso- para la población adulta, nos encontramos con que las propias bibliotecas catalogaban el producto como literatura infantil. Así pasó, sorprendentemente con dos álbumes ilustrados por Leandro Lamas y que dedicamos a la maternidad (Eu tamén son fonte y Mamá, ti si que me entendes): están siendo entregados a criaturas que no pueden entenderlos, sólo por estar "dibujados". De manera también bastante significativa en 2014 he visto como se traducía al español a cargo de Hoja de lata la novela Artes subversivas de cultivar jardines, a partir del original $A$ intervención. Pues bien, los editores vinieron a mí para publicar otra de mis novelas, ya traducida, aunque ellos, que la habían leído en gallego, no lo supiesen - lo que en sí mismo es indicativo de las dificultades de difusión que arrastran nuestros productos. Ante la imposibilidad de publicar lo ya publicado, se interesaron por este relato sobre activistas ecológicos y artistas, por la universalidad y atemporalidad de este motivo revolucionario. Probablemente la crítica ecológica implícita había determinado, sin embargo, que fuese la menos leída de mis obras en Galicia, donde la lectura militante implica que determinados temas resulten singularmente espinosos. Por esto también es importante para los autores y autoras de la literatura gallega salir al exterior, ser traducidos. 
Como para Edipo, la primera encrucijada de la literatura gallega, lógicamente, es la del ser. Finalmente, somos por contraposición al otro. Por eso no está de más la exposición de la herida a la vista pública, porque lo que procura el poder hegemónico es negar la herida misma. La lengua en Galicia no nos viene regalada como el aire que respiramos, ni entregada a cambio de unas monedas como el inglés a que, por dictado capitalista, siempre aspiramos. Hemos tenido que aprender a beber nuestra lengua de las personas de edad que la conservaron, muchas veces sin apego; hemos tenido que amasarla como pan con que nutrirnos diariamente; hemos tenido que expurgarla de tantas intromisiones externas que hemos hecho de ella bandera. Nos hemos convertido en jardineras que la cultivan para que sus raíces se ahonden en nuestras mentes y acaben corriéndonos por las venas. Luchar por la lengua con que nuestra tribu miró el mundo desde antiguo asegura nuestra dignidad y permite reconstruir colectivamente la identidad de un pueblo denigrado, en nombre de quien venga detrás. El poeta que escribió el himno gallego, Eduardo Pondal, dijo al morir, después de haber luchado por recuperar y dignificar el gallego a finales del siglo XIX algo que podríamos traducir como "Me habíais dado una lengua de hierro, os devuelvo una lengua de oro". Y ése es un canto que los estudiosos de cualquier literatura pueden entender y valorar. Más allá de preciosismos de virtuoso, nada hay más libre que la lengua: el espacio de la democracia radical y del diálogo.

Miguel Anxo Murado fue encargado hace unos años de presentar la realidad gallega al público editorial español y recogió al efecto - en un volumen ágil, que se deja devorar con ganas, Otra idea de Galicia-, la lista de heridas contra la galleguidad practicada por grandes escritores hispánicos: Tirso de Molina, Cervantes, Lope de Vega o Góngora usaron frases injuriosas contra nosotros, que se convirtieron en tópicos: los gallegos son sucios, cortos de entendimiento e interesados; las gallegas tienden a todos los vicios, en particular a los de cama —donde, además de las posibilidades conocidas, parece que las gallegas hemos inventado modalidades por conocer. En este contexto hay que leernos.

\section{Segunda encrucijada: la escritura hizo al pueblo}

La transmisión de conocimiento por vía escrita es el motor básico de la cultura occidental pero en Galicia tenemos razones particulares para adorar la literatura. Fue por escrito que aprendimos a reconocernos como nación diferenciada. ("Castellanos de Castilla, tratad bien a los gallegos; cuando van, van como rosas; cuando vienen, vienen como negros", cantó Rosalía de quien hago una traducción apresurada). Fue ver nuestra lengua, esa que llamaban rural y torpe, en letras impresas lo que alimentó nuestro orgullo y nos dio alas para volar por encima de las humillaciones precedentes. Fue el movimiento escrito de finales del siglo XIX, el Rexurdimento, protagonizado por escritores y escritoras - que hacían sus vidas en español pero que habían advertido el problema nacional- lo que inició el camino: la necesidad de recoger las formas gramaticales antes de que 
cayesen en desuso, la de componer una narrativa, la de dedicarse al ensayo; la de, en definitiva, dignificar la lengua. Sin los proyectos editoriales de las Irmandades da Fala, en la época de la I Guerra Mundial, o de Anxel Casal - que fue alcalde en Compostela durante la República y asesinado por el fascismo- no conservaríamos nuestra dignidad. Sin un galleguismo cívico y combatiente, el duro golpe de la guerra civil lo habría aplastado todo. Solo un dato editorial habla elocuentemente de este proceso que enuncio con rapidez. En 1916 el periódico $A$ nosa terra ve la luz porque consigue antes dos mil suscripciones como aval, lo que significa que en la Galicia rural de principios del siglo Xx la militancia galleguista intuía la importancia de la vía escrita. En otros territorios, un pueblo llega a un determinado grado de sofisticación cultural y crea una literatura. En Galicia fue exactamente al revés: fue la escritura la que hizo al pueblo. En un momento en que la diversidad cultural está afectada por la globalización; en que las formas de cultura escrita se ven agredidas por el impacto de las pantallas, la literatura gallega es una señal identitaria y una resistencia.

Intento clarificar esto porque se repite con excesiva alegría que fue el pueblo trabajador, campesino y marinero, quien conservó el legado de la lengua. Pero esto sólo es cierto en parte. Por supuesto, al declarar que la lengua es un producto de clase, proclamamos el orgullo de reconocer nuestra cultura como un artefacto de personas humildes, como una creación colectiva sometida al proceso histórico que vengo enunciando y condenada por ello a ser apenas marca de clases desfavorecidas. La literatura en Galicia gana con eso importancia política: no es una literatura surgida de la espontaneidad creativa, de la voluntad de expresarse por escrito de personalidades de élite con veleidades literarias; la literatura gallega es una declaración de intenciones. Un ejército de personas de distintas generaciones osa reivindicar esa lengua y asumir como propia una identidad colectiva despreciada, una forma de negritud, si se me permite usar tal expresión, para reapropiarnos de ella, como hicieron los movimientos del black power o el queer con otras identidades marginales para, en este caso, construir la nación soñada. Por eso no puede dejar de interesarles a los lectores y lectoras españoles que crean en la transformación social, que se consideren mestizos, multiculturales o universalistas. No puede dejar de interesar en Barcelona, en Nueva York o en Pequín. Digo esto porque a veces en Europa nacionalismo es sinónimo de imposición fascista o de chauvinismo pero en Galicia se trata apenas de una cuestión de autoestima: el nuestro no es un nacionalismo de opresores, sino de oprimidos. Ni queremos imponernos ni pensamos ser mejores que nadie. Simplemente somos un pueblo más del planeta, con tanto derecho a existir como los otros.

Llegado este punto, puede ser relevante destacar algo. En la sociedad actual se respeta que alguien tenga una identidad y la defienda. Homosexuales, emigrantes, minorías étnicas o pacientes aquejados por enfermedades raras constituyen asociaciones en defensa de sus intereses. A nadie en su sano juicio se 
le ocurriría pensar que esas defensas atentan contra el bien común. Si soy miope y pido que la miopía sea reconocida, no agredo a las gentes no miopes.

Pues si soy gallega y pido el reconocimiento de mi cultura, de mi identidad nacional, no agredo a madrileñ@s ni a murcian@s. La exposición de la herida gallega a la vista pública, la defensa de la lengua y de la cultura, es la melodía que nos distingue en la gran coral del mundo. Sin afrentas. Como la asociación de miopes que no ultraja a los que ven perfectamente.

Pero la literatura gallega no nace sólo de defender la lengua de nuestros mayores, del derecho a conservar la herencia del pasado, - la palabra herencia arrastra evocaciones rancias sobre sistemas de propiedad. Los escritores y escritoras, que también somos pueblo trabajador, sabemos del valor de la transmisión como proceso de construcción compartido y consciente. Y cuando el poder político intenta abrir una brecha en la sociedad, una "Galicia bilingüe" que encubre únicamente el supuesto derecho de algunos a no acercarse al gallego, nuestra literatura destapa el insidioso artefacto de la hegemonía del español. Ni siquiera es aceptable el supuesto derecho a escribir en la lengua materna, como si la única lengua posible fuese la primera que se habla, como si no fuese aceptable y transformador cambiar para instalarse en otra. La defensa del gallego concierne a las personas que recibieron la lengua en la primera infancia pero también, con todo derecho, a aquéllas que fueron criadas en español o en cualquier otra lengua y que asumieron un día, en un ejercicio de decisión consciente y solidario, que era en gallego como se querían construir para solidarizarse con las clases desfavorecidas, para denunciar una dominación. En la encrucijada importa repetir que la defensa del gallego y su cultura no tiene que ver con los propios intereses, sino con el deseo de apoyar una restitución histórica, con una ética de compromiso contra toda lógica de dominio.

\section{Tercera encrucijada: gallego-portugués o gallego-castellano}

Tal vez no sea muy comentado fuera de nuestras fronteras pero todos los problemas que vengo mencionando sobre la invisibilidad del gallego todavía se acrecientan con una dificultad adicional: la ortográfica. Dicho en breve, en el gallego actual litigan dos posturas: una, la oficial, amparada en prestigiosas instituciones, instauró una manera de escribir gallego apegada al español para facilitar la alfabetización; la otra, la reintegracionista, procura hermanar los productos culturales elaborados en Galicia con los procedentes de otras partes del mundo que hablan la misma lengua: Portugal, Brasil, Angola o Mozambique. Esta segunda versión ha crecido en las calles, al calor del activismo político y está proscrita para los certámenes y los laureles, aunque sea la más habitual en los centros sociales y allí donde se cocina diariamente la vitalidad de una sociedad. Doy, por supuesto, una visión de parte. He tomado partido pero no desinformada ni alocadamente - todavía me presentaban en un acto público hace unos meses como alguien que ha tomado una medida equivocada y que 
debe reflexionar y volver al redil-; sino como lingüista profesional y como escritora que ha renunciado a continuar recibiendo los premios que mi obra había cosechado. De nuevo, la encrucijada.

Muchos de los escritores y escritoras con obra amplia en gallego comenzamos a publicar en la ortografía oficial: Carlos Taibo, Séchu Sende, Dionísio Pereira, Víctor Vaqueiro o yo misma formamos parte de ese grupo que cambió de bando en esta guerra de grafías. Habíamos obtenido algún grado de reconocimiento en el panorama cultural y, después, dimos un paso adelante. Ese paso no por ser consciente deja de ser atrevido. Porque publicar en el padrón portugués es difícil - aunque las editoriales lisboetas estén comenzando a editarnos: personalmente acabo de publicar Uma mãe tão punk con Chiado en Lisboa. Pero lo cierto es que la crítica portuguesa la considerará gallega y la crítica gallega la ignora por portuguesa y no le auguro por ello muchas reseñas. Esta decisión exige una disposición adicional para inculturarse de nuevo, para negociar qué formas léxicas o gramaticales propias de Galicia no estamos en disposición de perder $y$, sobre todo, ha de afrontar que la sociedad gallega es pequeña, su cultura propia marginal y la modificación gráfica no resulta siempre popular ni bien comprendida. No entraremos en las instituciones de la cultura, seguiremos en la lucha pero ese gesto forma parte de la cultura de resistencia a que pertenecemos.

Que muchos autores adoptemos la ortografía del gallego internacional, de eso que comúnmente se llama portugués, puede parecer sorprendente en una época en que la lengua está siendo literalmente aplastada por el poder. Lo cierto es que much@s escritor@s, como much@s activistas, en Galicia sólo vemos ya posible para la revitalización del gallego un compromiso efectivo con la tradición del acuerdo ortográfico que nos mueve de nuestras fronteras: escribimos nuestra lengua aceptando las convenciones que ha ido adoptando al sur del Miño, donde se ha mantenido como lengua de estado, sin persecuciones ni condenas. Ésta es una valentía. El compromiso se adopta en un nivel ético y político y produce - no lo olvidemos - una exclusión voluntaria. Quien opta por incorporarse a esa tradición se queda en los márgenes del sistema y probablemente ni siquiera va a recibir el premio de ver difundida su obra fuera de esas fronteras de estado que tantos de nosotros, independentistas, querríamos destruir. Dijo Alejandro Magno al filósofo Diógenes: "Si obedecieses al rey, no tendrías que contentarte con unas lentejas". Y respondió Diógenes, rebelde: "Si te contentases con unas lentejas no tendrías que obedecer al rey". Diógenes sería reintegracionista, sin duda. La anécdota ilustra como pocas en qué consiste la autonomía moral, la libertad y la coherencia.

La encrucijada natural que nos obliga a decidir entre gallego-portugués y gallego-castellano se resuelve al darle una lectura política: la proximidad con el portugués se niega, reiteradamente y contra toda evidencia, porque resulta amenazadora, no sea que nos declaremos independientes; no sea que soñemos 
con ser algo distinto del galleguiño desaliñado y tonto. Sin embargo, la valentía de tantas firmas de la literatura gallega, que escriben fuera de las instituciones, de las grandes editoriales, fuera del establishment de la cultura, fuera de lo que escucharon en su infancia, fuera de toda convención, la valentía, digo, no puede quedarse suspensa en el aire.

Fuera de todos los parámetros de confort, hay algo fundamental para explicar la ferocidad con que nos adherimos a esta forma ortográfica: el estado español niega nuestra identidad y nuestra soberanía. El estado español nos confunde envolviéndonos bajo un manto de folclóricas, fiestas taurinas, paellas $y$ sol. El estado español desconsidera nuestra capacidad de decidir, nos trata como a menores de edad administrando nuestra hacienda y, todavía, se empeña en convencernos de que somos una región subsidiada por ese gigante benefactor que es la Unión Europea, aunque todas las personas conscientes e informadas sepan que las subvenciones no restituyen lo que damos en producción energética, por ejemplo. La insurrección frente a un estado, históricamente opresor, pero hoy además infectado de una corrupción generalizada está moviéndonos para adoptar estrategias múltiples, inclusive la ortográfica. El cambio de ortografía es todo menos anecdótico y cualquiera que haya publicado como yo algunas obras en la norma supuestamente oficial ILGA-RAG experimentará un deje de amargura al pasar al lado oscuro, al menos en relación a las editoriales que ahora se ponen de espaldas. En teoría, que una autora escriba en una norma $u$ otra debería ser precisamente eso, un dato anecdótico para una editora, que lo que pretende es vender libros. En términos exclusivos de negocio, la editorial podría incluso obtener algunas ventajas de abrir su catálogo de autor@s al reintegracionismo. Pero las grandes editoras son intransigentes. Si antes habían vendido millares de ejemplares de obras de una autora y ésta cambia de norma, le presentan sus respetos y le desean buena suerte, no sin antes advertir a la incauta de que acaba de suicidarse intelectualmente. Por eso, el paso al otro lado nos obliga a blindar nuestras posiciones. Para mí es difícil ser amablemente reintegracionista: ni ésta es una lucha trivial, ni se puede consentir esta exclusión. No deben vetarnos.

\section{Cuarta encrucijada: Literaturas modernas en sociedades perifé- ricas o los márgenes como motor}

Siendo Galicia un país empobrecido y periférico, es posible pensar que la suya será una cultura de segunda: una cultura regional, hecha de apego a lo rural, de costumbrismo y de pequeñas composiciones folclóricas. Nada de eso queda más alejado de la realidad. La literatura gallega existe sin tregua a partir de la Edad Media y, aún definiéndose en términos de clase, como cultura de camadas trabajadoras y oprimidas, ha contado en todos los tiempos con ensayo, con obras de pensamiento y en la contemporaneidad con textos de instrucción política, con debate de ideas y periódicos. Voy a poner un solo ejemplo de su indomable 
modernidad intentando enunciar que por definición la literatura gallega es una literatura queer o, mejor, la literatura de una queer nation.

En un ensayo sobre teoría queer, ${ }^{1}$ me he ocupado del curioso tratamiento de la homosexualidad en la literatura gallega. Pretendía ilustrar que estamos ante una literatura singular, madura y moderna, y no precisamente ante un catálogo costumbrista. En una sociedad como la gallega, frecuentemente tachada de conservadora, parecería imposible que los relatos sobre un comportamiento sexual desviado de las normas llegasen a la imprenta. Sin embargo, la homosexualidad declarada o las pulsiones de insatisfacción con las sexualidades canónicas aparecieron en lengua gallega, incluso mucho antes que en la española: estaban en nuestros clásicos, de manera rotunda, valiente y conmovedora.

En este sentido, la etiqueta de literatura homosexual no debería reducirse a los textos escritos por personas que quieren comentar que realizan prácticas homosexuales, ni siquiera a quien introduzca personajes con experiencias homosexuales. Como viene siendo habitual en el activismo, podría calificarse como tal todo texto que pueda ser interpretado como un artefacto para desestabilizar la heteronormatividad de las creaciones culturales, quiere esto decir, los textos con autor o autora heterosexual, que utilice repertorios leídos o legibles en clave de alteridad sexual. Esto es lo que se observa repetidamente en una literatura tan rica como la gallega y, como indicaba antes, no sólo en los últimos años, al calorcillo de los movimientos de liberación LGBT: al contrario. Diferentes estudiosos han notado como la homosexualidad servía para denunciar la opresión que una sociedad alienada y colonizada ejercía sobre los individuos y han ejemplificado con poemas de Rosalía de Castro, con cuentos de Otero Pedrayo o con las novelas de Blanco Amor. Hasta donde yo conozco, en la literatura española no hay nada parecido. Cuando Beatriz Gimeno quiso desmontar el tópico de la lesbiana perversa, a partir del tratamiento periodístico concedido al caso real del asesinato de Rocío Wannikhof, era ya 2009. Siendo la gallega una literatura contra-poder, tampoco es tan extraño que se explore lo sexualmente raro, lo alternativo, lo incógnito. Pero si nuestros clásicos son susceptibles de lecturas tan radicales, y anunciaron tanta modernidad, la literatura gallega no puede jugar en regional.

En 2008 el escritor gallego Mario Regueira defendía la literatura gallega como una literatura maronda, un término aplicado habitualmente a los animales sin castrar y figuradamente al homosexual que no quiere o no puede ocultar su condición. Regueira lo rescata como "resistente a la mutilación" y propone comparar el movimiento queer con la situación histórica de la lengua gallega, de manera que: (a) cuestiona la tradición normativizadora de la crítica y sus cortes en generaciones literarias - que anulan los espacios de transición-, al tiempo

\footnotetext{
${ }^{1}$ Todas las referencias a continuación proceden de Moure, T. (2012), Queer-emos un mundo novo, Vigo, Galaxia.
} 
que (b) considera la literatura gallega como un producto cultural elaborado contra el poder estatal. Igual que el queer interpreta el dualismo sexual como un arma de doble filo, Regueira considera que el escaso reconocimiento de nuestra literatura a escala estatal oculta el oscurecimiento del independentismo como tema literario, o la marginación de la literatura en normativa reintegracionista. La literatura gallega, concluye el autor, (c) debe asumir con orgullo los apelativos de anormalidad o subalternidad porque fue esa relación de poder la que determinó una de las producciones más originales y arriesgadas de Europa.

La visión de la literatura gallega como queer (o maronda) me ha parecido muy interesante. El marondo cae fuera de las categorías y rompe la normalidad. De un lado, tenemos una nación sin estado, algo que no se refleja en unas fronteras en el mapa ni consigue reconocimiento en el derecho internacional pero que tampoco es una simple región puesto que tiene una cultura propia. $\mathrm{O}$, igualmente, tenemos una lengua afectada de los problemas sociales antes mencionados; un idioma que, en términos de uso real, está siendo interpretado por el pueblo que lo habla como una semi-lengua. De ahí parte, sin embargo, una producción literaria contra-poder, rica y poliédrica, que introduce novedades impensables en cada momento histórico: pensemos en el carácter innovador de las cantigas de amigo en su época, en la radical modernidad de la literatura feminista y política de Rosalía en el XIX, o de Blanco Amor entre los escritores realistas del XX. Sin embargo esa literatura tiende a verse poco traducida y citada internacionalmente, por los problemas de oscurecimiento que rodean al hecho nacional. Tenemos, por otra parte, las teorías de la posmodernidad y la ruptura con lo que está establecido, con las categorías de sí o no, en una época marcada por los grises. La conexión es obvia puesto que en Madrid siempre se ha dicho de los gallegos que no se sabe si subimos o bajamos. Estamos en medio, efectivamente: somos una queer nation.

Más allá de las categorías, la literatura gallega es subversiva por definición; está provista de toda la autenticidad de quien se reconoce como un individuo raro, un sujeto inestable, apenas constituido en el tiempo, en perpetua variación.

\section{Conclusión}

Revisadas las encrucijadas, podrá entenderse la hipótesis inicial: por qué la literatura gallega cumple, como Edipo, un destino trágico. Una literatura que construye una nación, que se levanta contra la lengua dominante, que obliga a elegir entre tradiciones ortográficas distintas y a producir militancia, en el sentido bélico de la expresión, difícilmente puede ser regional y costumbrista. Está condenada, como Edipo, a habitar la encrucijada -ése es su destino trágico- . No debe seguirse de aquí una declaración de victimismo. Al contrario, Edipo es también un rebelde, alguien que no se somete a lo normativo, porque la encrucijada donde se decide su destino es un espacio para optar entre las mentiras fáciles y las verdades incómodas. La encrucijada puede arrojarnos a los 
márgenes, pero los márgenes son, por definición, un espacio para la libertad y para la disidencia. Eso es lo que todavía no está escrito en el hegemónico español; sí en la literatura gallega.

\section{cc) (1) $(9)$}

